\title{
Seizures and movement disorders: phenomenology, diagnostic challenges and therapeutic approaches
}

\author{
Maria Eliza Freitas, ${ }^{\oplus 1}$ Marta Ruiz-Lopez, ${ }^{2}$ Josep Dalmau, ${ }^{3}$ Roberto Erro, ${ }^{\oplus}$ \\ Michael Privitera, ${ }^{5}$ Danielle Andrade, ${ }^{6}$ Alfonso Fasano ${ }^{\oplus}$
}

${ }^{1}$ Medicine, McMaster University Division of Neurology, Hamilton, Ontario, Canada

${ }^{2}$ Service of Neurology,

Fundación Jimenez Diaz University Hospital, Madrid, Spain

${ }^{3}$ Department of Neurology, University of Pennsylvania, Philadelphia, Pennsylvania, USA ${ }^{4}$ Department of Medicine, Surgery and Dentistry 'Scuola Medica Salernitana', University of Salerno, UCL Institute of Neurology, Baronissi, Italy ${ }^{5}$ Epilepsy Center, University of Cincinnati Gardner Neuroscience Institute, Cincinnati, Ohio, USA

${ }^{6}$ Neurology, Toronto Western Hospital, Toronto, Ontario, Canada

${ }^{7}$ Neurology, Krembil Brain Institute; Movement Disorders Centre and the Edmond I Safra Program in Parkinson's Disease, Toronto, Ontario, Canada

\section{Correspondence to}

Dr Alfonso Fasano, Neurology, Movement Disorders Centre and the Edmond I Safra Program in Parkinson's Disease, Toronto, Ontario, Canada; alfonso. fasano@gmail.com

Received 21 November 2018 Revised 6 February 2019 Accepted 7 February 2019 Published Online First 22 February 2019

Check for updates

(C) Author(s) (or their employer(s)) 2019. No commercial re-use. See rights and permissions. Published by BMJ.

To cite: Freitas ME, Ruiz Lopez M, Dalmau J, et al. J Neurol Neurosurg Psychiatry 2019:90:920-928.

\section{ABSTRACT}

Seizures and movement disorders (MDs) are distinct neurological conditions presenting with abnormal movements. Despite sharing an overlap in phenomenology, these movements have different origins. In order to explore the overlaps and the narrow boundaries between these two conditions, we performed a review of the literature to explore the risk of seizures in MDs. We discussed the mimics and chameleons including MDs that look like seizure (eg, paroxysmal dyskinesia, status dystonicus) and seizures that look like MDs (eg, epilepsia partialis continua, nocturnal frontal lobe epilepsy). Additionally, we examined the therapeutic challenges as well as the anatomical and chemical pathways relevant in the interplay between epilepsy and MDs. Finally, we proposed an algorithm to guide clinicians towards the final diagnosis of conditions characterised by the co-occurrence of MDs and seizures.

\section{INTRODUCTION}

Movement disorders (MDs) are a group of neurological conditions characterised by abnormal movements that commonly arise from an altered function in the nuclei of the basal ganglia or their connections. ${ }^{1}$ Seizures are defined as 'a transient occurrence of signs and/or symptoms due to abnormal excessive or synchronous neuronal activity in the brain', whereas epilepsy is a brain disease characterised by one or more seizures with a relatively high recurrence risk. ${ }^{2}$

In spite of being caused by several different conditions, both MDs and seizures display abnormal movements with overlapping phenomenology. Given these phenomenological similarities as well as possible aetiological commonalities, clinicians are often challenged by conditions at the boundaries between epilepsy and MDs. In fact, several syndromes may exhibit coexisting abnormal movements from epileptic or non-epileptic origin regardless of the causes, which can overlap or be distinct.

This review aims to gather all the most updated literature with the ultimate goal of navigating clinicians through the complex interplay between MDs and seizures. We will discuss the seizure semiology and the risk of epileptic activity in MDs primarily presenting hypokinetic or hyperkinetic movements (or a combination of both). Most importantly, we will address the mimics that often pose challenges, including MDs that look like epileptic disorders and seizures that look like MDs.
Lastly, we will discuss the anatomical and chemical pathways involved in the overlap between seizures and MDs, as well as the treatment approaches. Moreover, we propose an algorithm to guide clinicians towards the final diagnosis of conditions characterised by the co-occurrence of MDs and seizures.

The most recent nomenclature of genetic MDs and the new revised operational classification by the International League Against Epilepsy will be used in this review. ${ }^{34}$ In each section, the disorders will be listed in order of prevalence, starting with the most frequent ones.

\section{SEARCH METHODS}

This review was conducted through a literature review in Medline and Embase databases of articles published between 1 January 2013 and 1 April 2018. Only articles in English and on humans were included. The search strategy included the combination of the following terms: ((seizures) OR (epilepsy)) AND ((movement disorders) OR (chorea) OR (tremor) OR (stereotypies) OR (parkinsonism) OR (ataxia) OR (dystonia) OR (dyskinesia) OR (tics) OR (myoclonus) OR (paroxysmal movement disorders)). The initial search identified 604 articles. Among those, 57 articles were selected according to the presence of pertinent terms in the abstract and title. Additional references, identified from the reference list of included articles but that were not part of the original search results, were included at authors' discretion. We focused on the scientific literature of the past 5 years, but also included older publications of high merit or originality.

\section{RISK OF SEIZURES IN MDS}

Among the hypokinesias, Parkinson's disease (PD) is one of the most prevalent neurodegenerative disorders worldwide. The relation between PD and seizures has been controversial, with small studies showing a positive correlation, but generally with a low prevalence of seizures in patients with PD. ${ }^{5}$ However, a more recent study demonstrated that patients with PD who did not have any seizure-provoking comorbidity had an adjusted OR of epileptic seizures of 2.24 compared with PD-free individuals without any seizure-provoking comorbidity. ${ }^{6}$ Although the association between PD and seizures remains unclear, superimposed brain disorders such as cerebrovascular disease, infections, surgery and trauma tend to be more strongly associated with seizures in patients with PD. ${ }^{6}$ 


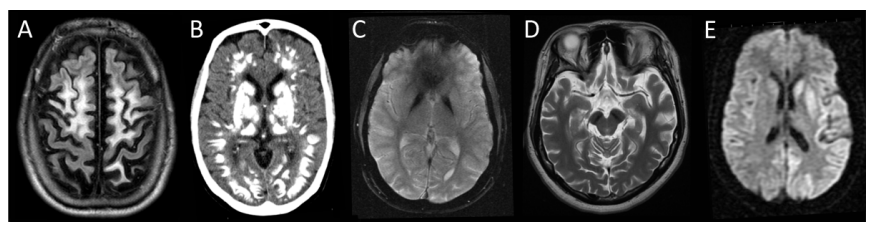

Figure 1 Some illustrative imaging features of the reviewed conditions. (A) Wilson's disease with generalised seizure: white matter lesions with cortical and subcortical hyperintensities; (B) Fahr's disease (CT scan): calcium deposition with hyperdensities in the basal ganglia and subcortical areas; (C) pantothenate kinase-associated neurodegeneration (PKAN) due to PANK2 mutation: the 'eye of the tiger' sign showing a central T2 relatively hyperintense spot within the hypointense globus pallidus due to gliosis and vacuolisation; (D) beta-propeller protein-associated neurodegeneration: small linear low signal areas within the expected locations of the substantia nigra in T2 sequence; (E) Creutzfeldt-Jakob disease: hyperintensity in the cortex, the left lentiform nucleus and in the left caudate nucleus on diffusion-weighted imaging.

DYT-ATP7B or Wilson's disease is a hepatolenticular degeneration due to mutations in the $A T P 7 B$ gene leading to an impaired copper metabolism. ${ }^{7}$ Majority of patients exhibit neurological and hepatic symptoms. DYT-ATP7B may display hypokinetic or hyperkinetic movements. Seizures can occur in approximately $10 \%$ of patients, including generalised tonic-clonic (GTC) and focal onset seizures. ${ }^{8}$ Patients with seizures more often have white matter changes than those without (figure 1A). ${ }^{8}$

Idiopathic basal ganglia calcification, formerly known as Fahr's disease, is characterised by abnormal deposition of calcium in the basal ganglia and other parts of the brain (figure 1B), which leads to hypokinetic or hyperkinetic movements combined with dementia, neuropsychiatric symptoms and GTC seizures. ${ }^{9}$ It is a rare inherited or sporadic neurological condition due to genetic causes or secondary to an endocrine disorder (eg, hypoparathyroidism or pseudohypoparathyroidism). Mutations in SLC20A2, $P F B C, P D G F B$ and PDGFRB have been associated with Fahr's disease, with $S L C 20 A 2$ being the most common causative gene. ${ }^{9}$ Presence of parkinsonism is more often seen in SLC20A2 mutations, headache in PDGFB and GTC seizures in patients with pseudohypoparathyroidism. $^{10}$

Cerebrotendinous xanthomatosis (CTX) is a rare autosomal recessive inborn disorder of bile acid metabolism due to mutations in the CYP27A1 gene. GTC seizures and parkinsonism are the initial neurological features of CTX. Xanthomas are one of the hallmarks of this condition and usually begin to form in early adulthood and most commonly seen in tendons. ${ }^{11}$

Neurodegeneration with brain iron accumulation (NBIA) is a group of disorders characterised by excess iron accumulation in the globus pallidus and other areas, depending on the underlying genetic abnormality (figure $1 \mathrm{C}-\mathrm{D}$ ). ${ }^{12}$ NBIA clinically presents as progressive hypokinetic and/or hyperkinetic MDs with a variable degree of cognitive and psychiatric involvement. ${ }^{12}$ The most common NBIAs presenting seizures are PLA2G6-associated neurodegeneration, beta-propeller protein-associated neurodegeneration, mitochondrial membrane protein-associated neurodegeneration and fatty acid hydroxylase-associated neurodegeneration. Although rare, seizures have also been reported in NBIA/DYT/PANK2 and aceruloplasminaemia.

Huntington's disease (CHOR-HTT) is a hereditary neurodegenerative condition caused by a CAG repeat expansion in the HTT gene leading to chorea, cognitive deterioration and psychiatric problems. ${ }^{13}$ Seizures are more common in juvenile Huntington's disease (onset before age 21), whereas chorea is less common. ${ }^{14}$ Seizures have also been reported in Huntington's disease-like syndromes, such as CHOR-PRNP or HDL1, and SCA-TBP or HDL4/SCA17, but not in CHOR-JPH3 or HDL2. ${ }^{13}$

Chorea-acanthocytosis (CHOR-VPS13A) and McLeod syndrome (CHOR-XK) are characterised by neurodegeneration of the basal ganglia and red cell acanthocytosis. ${ }^{13}$ CHORVPS13A is a rare autosomal recessive neurodegenerative disorder due to mutations in the vacuolar protein sorting 13 homolog A (VPS13A). Seizures are rare, but can be the first symptom in unusual presentations. ${ }^{15} \mathrm{CHOR}-\mathrm{XK}$ is inherited in an $\mathrm{X}$ linked matter and is caused by mutations in the XK gene encoding an antigen of the Kell blood group system. ${ }^{13}$ Cardiomyopathy and arrhythmia are distinguishing features and patients can also display seizures.

Spinocerebellar ataxias (SCAs) are a group of clinically and genetically heterogeneous neurodegenerative disorders characterised by progressive ataxia and a broad spectrum of other neurological findings. Seizures are rare, being reported in 5\% of patients at disease onset. ${ }^{16}$ Dentatorubral-pallidoluysian atrophy (DRPLA) is the condition with the highest prevalence of seizures among the dominant cerebellar ataxias; however, seizures have also been reported in SCA 10, 17, 19 and $22 .{ }^{16}$ DRPLA is caused by a CAG trinucleotide repeat expansion and is characterised by various combinations of cerebellar ataxia, choreoathetosis, myoclonus, epilepsy, dementia and psychiatric symptoms. ${ }^{17}$ Epileptic seizures are a common feature in all patients with onset before the age of 20, whereas the occurrence of seizures in patients with onset after the age of 40 is rare. ${ }^{17}$ Tonic, clonic or GTC seizures are observed in DRPLA. ${ }^{17}$

Autosomal dominant cortical tremor, myoclonus and epilepsy are a non-progressive disorder with an age of onset of 12-50 years characterised by the variable combination of 'cortical tremor', myoclonus and seizures (mostly GTC). ${ }^{18}$ Cortical tremor is an action and postural fine shivering movement consisting of continuous, arrhythmic, mainly distal, fine twitches in the hands resembling essential tremor. A neurophysiological study can help to distinguish cortical tremor versus essential tremor. Usually, patients have significant clinical improvement with antiepileptic drugs including valproate and clonazepam.

Tourette syndrome (TS) is characterised by multiple motor tics with at least one vocal tic and a high rate of psychiatric comorbidities. In a recent retrospective cohort study, the TS group had an 18.4-fold increased risk of seizures than the control group. ${ }^{19}$ Even after adjusting for comorbidities, the risk of seizures in the TS group remained high. Although this single study suggested a higher risk of seizures, the aetiological link between seizures and TS remains to be investigated and further studies are warranted.

Alternating hemiplegia of childhood (AHC) is associated with a variety of neurological features including episodes of hemiplegia and choreoathetosis. AHC is associated with mutations in ATPase $\mathrm{Na}+/ \mathrm{K}+$ transporting subunit alpha 3 (ATP1A3) gene. Epileptic seizures may occur around the time of onset of hemiplegic attacks, including GTC, focal seizures and status epilepticus (SE). Approximately $50 \%$ of patients with AHC experience a seizure at least once in their lifetime. More recently, two cases of AHC phenotype were described with mutations in ADCY5 gene (see below). ${ }^{20}$

Stiff-person spectrum disorder comprises the stiff-person syndrome (SPS), a segmental form called stiff-limb syndrome and the more severe disease called progressive encephalomyelitis with rigidity and myoclonus (PERM). SPS presents muscle rigidity and painful spasms that occur spontaneously or are triggered by diverse stimuli. Overall, seizures are a rare symptom: a few cases have been described in SPS, but it is most often 
associated with PERM, in which seizures have been found in approximately $13 \%$ of patients. ${ }^{21}$

$\mathrm{N}$-methyl-D-aspartate receptor (NMDAR) antibody-associated encephalitis is a disorder associated with the presence of autoantibodies directed against the extracellular domain of the NR1 subunit of the NMDAR. ${ }^{22}$ NMDAR encephalitis can present a broad spectrum of hyperkinetic movements including oro-lingual-facial dyskinesias (most common MDs), limb and trunk choreoathetosis, elaborate motions of arms and legs, oculogyric crisis, dystonia, rigidity, and opisthotonic postures. ${ }^{23}$ Seizures can take place at any time during the disease, but tend to occur earlier in males. ${ }^{23}$ The most common type of seizures seen are GTC, focal impaired awareness seizures (FIAS) and focal to bilateral tonic-clonic seizures. Refractory SE and epilepsia partialis continua (EPC) can occur at any time during the illness. Seizure frequency and intensity tend to decrease as the disease evolves. Residual epilepsy is very infrequent after recovery.

Tonic-dystonic seizures (TDS), previously called faciobrachial dystonic crises, are considered the prototype of the borderline between MD and seizures. TDS are associated with antibodies against the neuronal target LGI1 protein and are characterised by very brief and frequent episodes of abnormal posturing affecting mostly the arm and ipsilateral face and leg. ${ }^{24}$ TDS often overlap with other types of seizures, such as autonomic, temporal lobe and GTC. ${ }^{25}$ These type of seizures often precede the development of limbic encephalitis and other symptoms of LGI1 antibody-mediated encephalitis; therefore, prompt recognition and treatment with immunotherapy of TDS may prevent the development of full-blown encephalitis. ${ }^{25}$

Contactin-associated protein-like 2 (CASPR2) is another specific target protein in cases of autoimmune encephalitis. Some clinical features may differentiate patients with antibodies against these two components (LGI1 and CASPR2) of the voltage gated potassium channel complex (VGKC).$^{22}$ For example, the presence of TDS and hyponatraemia strongly suggests LGI1 reactivity, whereas the presence of neuromyotonia or other features of Morvan's syndrome (eg, thymoma) suggests CASPR2-directed autoantibodies (sometimes accompanied by LGI1 antibodies).

Most antibody-mediated encephalitis can manifest with seizures and less frequently with MDs. ${ }^{22}$ The ones more frequently associated with seizures are those related to antibodies against inhibitory receptors such as neurotransmitter gamma-aminobutyric acid receptors type A and B (GABAa and GABAb receptors). ${ }^{26}$ In young children, anti-GABAaR encephalitis can mimic anti-NMDAR encephalitis. ${ }^{26}$ In young patients with encephalitis and prominent symptoms of basal ganglia dysfunction (chorea, parkinsonism, dystonia), the encephalitis associated with antibodies against dopamine 2 receptor should be considered, although this is extremely rare. ${ }^{22}$

Lastly, among the context of autoimmune MDs, Hashimoto's encephalopathy is defined by the combination of neuropsychiatric symptoms, laboratory evidence of antithyroid antibodies and prominent clinical improvement with steroids, along with lack of evidence of other disorders. ${ }^{27}$ Clinical features include confusion, hallucinations, seizures, SE, tremor, myoclonus, gait ataxia, palatal myoclonus or chorea. ${ }^{27}$ High titres of antithyroid peroxidase antibodies are usually observed; however, most patients are euthyroid or have subclinical hypothyroidism; overt hypothyroidism occurs in $20 \%$ of cases. Back-averaged electroencephalogram (EEG) does not show a cortical correlate with myoclonus, suggesting a subcortical origin.

Subacute sclerosing panencephalitis (SSPE) typically results from persistent measles virus infection at a young age. Myoclonus is the most common and frequently the first symptom. ${ }^{28}$ Rare and less typical presentations of SSPE include seizures, EPC, acute encephalopathy, hemiparesis, acute ataxia, unilateral dystonia or psychiatric disturbances.

Creutzfeldt-Jakob disease (CJD) is a rapidly progressive transmissible spongiform encephalopathy that can be familial, sporadic or acquired. The typical clinical triad consists of rapidly progressive dementia, startle myoclonus, and characteristic periodic sharp complexes on the EEG and peculiar findings on MRI (figure 1E). ${ }^{29}$ Seizures are an uncommon finding in CJD, occurring in less than $15 \%$ of patients, and atypical presentations have been previously reported including non-convulsive SE and EPC. ${ }^{30}$

\section{MIMICS AND CHAMELEONS}

\section{MDs that look like seizures}

These are MDs that look like seizures due to the occurrence of episodic involuntary movement. Subcortical mechanisms are involved, thus explaining why EEG does not show epileptic activity in most cases.

Hemifacial spasm (HFS) is an MD of the seventh cranial nerve which is characterised by either brief or persistent, intermittent twitching of the muscles innervated by the facial nerve. ${ }^{31}$ Primary HFS likely results from compression of the seventh nerve at the root exit zone in the posterior cranial fossa by an aberrant or ecstatic vessel, whereas secondary causes are seen after VII nerve palsy or brainstem lesions. ${ }^{31}$ HFS may be mistaken for EPC involving the face (see below). ${ }^{32}$

Periodic limb movements (PLMS) are sleep-related phenomena characterised by periodic episodes of repetitive and highly stereotyped limb movements, which most often occur in the lower extremities. PLMS can be associated with brief arousals in sleep and autonomic reaction, and is defined as the presence of $>15$ movements per hour and a complaint of insomnia and/or excessive daytime sleepiness with no other explanation for these symptoms. ${ }^{33}$ PLMS are frequently seen in restless legs syndrome but can also occur in sleep disordered breathing, narcolepsy and rapid eye movement (REM) sleep behaviour disorder, as well as in several medical conditions, like renal failure, essential hypertension and PD, or associated with medication intake (antidepressants and neuroleptic agents). ${ }^{33}$ PLMS may mimic focal seizures, and in some cases further investigation (eg, EEG) is required. ${ }^{34}$

Status dystonicus (SD) is currently defined as 'a movement disorder emergency characterized by severe episodes of generalized or focal hyperkinetic movements that have necessitated urgent hospital admission because of the direct life-threatening complications of these movements'. ${ }^{35}$ SD can be triggered by precipitating factors such as infections, medication adjustments, surgical procedures, metabolic disorders and failure of deep brain stimulation. SD usually occurs as a result of a continuum of worsening dystonia with a preserved level of consciousness and normal EEG. Cerebral palsy, NBIA/DYT-PANK2, DYT-TOR1A, DYT-ATP7B and mitochondrial disorders are the main aetiologies of SD. ${ }^{35}$

Rare tremor syndromes may be episodic and mimic seizures; the differential diagnosis may include EPC and myoclonus. ${ }^{36}$ These syndromes are limb-shaking transient ischaemic attacks syndrome, hereditary chin tremor, paroxysmal head tremor, bobble-head doll syndrome, spasmus nutans and shuddering attacks (table 1).

Paroxysmal dyskinesias are an important paradigm of the overlap between MDs and seizures. ${ }^{37}$ It is a heterogeneous 
Table 1 Episodic tremor syndromes

\begin{tabular}{|c|c|c|c|c|c|c|}
\hline Syndrome & Age at onset & Cause & Phenotype & Duration & Recurrence & Triggers \\
\hline Limb shaking & Adulthood. & $\begin{array}{l}\text { Vascular: severe carotid } \\
\text { stenosis }(>80 \%)\end{array}$ & $\begin{array}{l}\text { Typically unilateral, upper limb } \\
\text { jerking tremor. }\end{array}$ & $\begin{array}{l}\text { Transient-may } \\
\text { last several } \\
\text { minutes. }\end{array}$ & $\begin{array}{l}\text { Episodes occur } \\
\text { monthly or up to } \\
\text { several times per day. }\end{array}$ & $\begin{array}{l}\text { Orthostatic positional } \\
\text { change, hypotension, } \\
\text { hyperventilation, neck } \\
\text { extension or walking. }\end{array}$ \\
\hline Hereditary chin tremor & Adolescence. & $\begin{array}{l}\text { AD linked to chromosome } \\
9 q 13-q 21 \text { in one family. }\end{array}$ & $\begin{array}{l}\text { Oscillatory rhythmic movements of } \\
\text { the chin muscles, mainly the mentalis }\end{array}$ & Seconds to hours. & Daily. & Emotion or anxiety. \\
\hline
\end{tabular}
9q13-q21 in one family. the chin muscles, mainly the mentalis

muscle.

Frequency varies between 2 and

$11 \mathrm{~Hz}$.

\begin{tabular}{|c|c|c|c|c|c|c|}
\hline $\begin{array}{l}\text { Paroxysmal head } \\
\text { tremor }\end{array}$ & Adulthood. & $\begin{array}{l}\text { Heterogeneity: missense } \\
\text { mutation in CACNA1A } \\
\text { gene, encoding the calcium } \\
\text { voltage-gated channel. }\end{array}$ & $\begin{array}{l}\text { Progressive disorder with 'no-no' } \\
\text { pattern and frequency of 3-5 } \\
\text { Hz involving the splenius and } \\
\text { sternocleidomastoid muscles. }\end{array}$ & 5 and $60 \mathrm{~min}$. & $\begin{array}{l}\text { Up to several times } \\
\text { a week. }\end{array}$ & No specific triggers. \\
\hline $\begin{array}{l}\text { Bobble-head doll } \\
\text { syndrome }\end{array}$ & Childhood. & $\begin{array}{l}\text { Expansion in the region of } \\
\text { the Ill ventricle resulting } \\
\text { from a suprasellar } \\
\text { arachnoid or a cyst. }\end{array}$ & $\begin{array}{l}\text { Episodic } 2-3 \mathrm{~Hz} \text { 'yes-yes' tremor of } \\
\text { the head with occasional 'no-no' } \\
\text { movements. } \\
\text { Other areas: neck, shoulders, trunk or } \\
\text { upper limbs. }\end{array}$ & Variable. & Variable. & $\begin{array}{l}\text { Absent during sleep. } \\
\text { Amplitude increases with } \\
\text { walking or excitement and } \\
\text { decreases or disappears } \\
\text { under volitional control or } \\
\text { concentration. }\end{array}$ \\
\hline Spasmus nutans & Childhood. & Idiopathic and benign. & $\begin{array}{l}\text { Head shaking, nystagmus, and } \\
\text { abnormal head posture or torticollis. } \\
\text { Reminiscent of bobble-head doll } \\
\text { syndrome. }\end{array}$ & Variable. & Variable. & $\begin{array}{l}\text { Absent during sleep. } \\
\text { No triggers. }\end{array}$ \\
\hline Shuddering attacks & Childhood. & Idiopathic and benign. & $\begin{array}{l}\text { Brief bursts of rapid, shivering-like } \\
\text { movements of the head and both } \\
\text { arms. }\end{array}$ & Seconds. & $\begin{array}{l}\text { Up to } 100 \text { episodes } \\
\text { per day. }\end{array}$ & No triggers. \\
\hline
\end{tabular}

$A D$, autosomal dominant

group of disorders characterised by episodes of abnormal involuntary movements (dystonic, choreiform, ballistic) without loss of consciousness and sometimes preceded by a sensory aura. These movements can be mistaken for focal seizures including focal aware seizure (FAS) or FIAS. Although in paroxysmal dyskinesias scalp EEG does not show ictal discharges, many frontal lobe seizures that look like dyskinesias can also present normal EEG. Paroxysmal dyskinesia can be subdivided into three clinical syndromes: paroxysmal exercise-induced dyskinesia (PED), paroxysmal kinesigenic dyskinesia (PKD) and paroxysmal non-kinesigenic dyskinesia (PNKD), each of which is associated with the known causative genes SLC2A1, PRRT2 and $P N K D$, respectively, although a certain genetic heterogeneity is recognised (table 2). ${ }^{38}$ Glucose transporter type- 1 deficiency syndrome (GLUT1DS) is also caused by mutations in SLC2A1 presenting early-onset refractory seizures, PED and MDs. ${ }^{38}$ Approximately $90 \%$ of patients have clinical seizures, mainly GTC, followed by absence, myoclonic and focal onset seizures. ${ }^{39}$ PRRT2 mutations can also produce epileptic disorders. Benign familial infantile seizure (BFIS) is an autosomal dominant syndrome characterised by brief seizures featuring motor arrest, cyanosis, hypertonia and limb jerks with onset between 3 and 12 months of age that generally remit before the age of 2 years. Up to $80 \%$ of cases with BFIS have PRRT2 mutations. Analogously, almost $90 \%$ of cases with ICCA syndrome (infantile convulsions and choreoathetosis) carry PRRT2 mutations. This syndrome is characterised by infantile convulsions that are followed by the development of PKD, usually by the age of 5 years. ${ }^{37}$ More recently, a number of different genetic disorders have also been reported to cause paroxysmal dyskinesia associated with epilepsy. This is the case of mutations in the KNCMA1 gene that produce a syndrome of PNKD and epilepsy, either in the form of absence or GTC. ${ }^{37}$ Mutations in the SCN8A cause a variety of seizure types along with episodes of paroxysmal dystonia, sometimes resembling PKD. ${ }^{37}$ Furthermore, ECHS1 mutations and pyruvate dehydrogenase complex deficiency can also produce both epilepsy and paroxysmal dyskinesia, usually embedded in a more complex syndrome of lactic acidosis and encephalopathy. ${ }^{40}$

Startle syndrome is another example of paroxysmal disorder and should be included in the differential diagnosis of epileptic seizures. It includes hyperekplexia, stimulus-induced disorders (which can be epileptic or not), and neuropsychiatric syndromes such as startle-induced tics, culture-specific disorders (eg, Latah) and functional startle syndromes. ${ }^{41}$ The most relevant disorder is hyperekplexia, which is characterised by generalised stiffness at birth, excessive startle reflexes and generalised stiffness following startle; it is usually associated with mutations of the glycine receptor. ${ }^{41}$ The preserved consciousness and normal EEG distinguish it from epileptic seizures.

Patients with ADCY5 gene mutations (CHOR/DYT-ADCY5) have been associated with heterogeneous syndromes with a broader variety of MDs, such as dyskinesias (chorea, myoclonus, ballism or choreoathetosis); axial hypotonia that leads to a distinctive 'frog-like' ambulation; dystonic spasms; spasticity; or eye movement abnormalities. ${ }^{42}$ A notable characteristic of these patients is that dyskinesias have nocturnal exacerbations, which often lead to the suspicion of a seizure disorder, although video EEG telemetry is invariably negative in all the patients reported. A relation between CHOR/DYT-ADCY5 and seizures is not completely established, but only 1 of the 20 patients described in the largest cohort published to date had associated seizures. ${ }^{42}$

\section{Epilepsy that looks like MDs}

These are seizures (with EEG-confirmed cortical origin) causing involuntary movements resembling MDs from a phenomenological standpoint.

Focal seizures are classified according to the level of awareness (FAS or FIAS) and can display motor onset or non-motor onset, reflecting the first prominent sign or symptom in the seizure. ${ }^{2}$ 


\begin{tabular}{|c|c|c|c|c|c|c|}
\hline $\begin{array}{l}\text { Principal } \\
\text { causative gene }\end{array}$ & $S L C 2 A 1$ & PRRT2 & PNKD & KNCMA1 & SCN8A & $\begin{array}{l}\text { ECHS1 and PDC } \\
\text { deficiency }\end{array}$ \\
\hline $\begin{array}{l}\text { Main clinical } \\
\text { syndrome }\end{array}$ & PED. & PKD. & PNKD. & PNKD + epilepsy. & PKD + epilepsy. & PED + epilepsy. \\
\hline $\begin{array}{l}\text { Phenomenology } \\
\text { and clinical } \\
\text { features }\end{array}$ & $\begin{array}{l}\text { Duration of episodes: } \\
\text { few minutes up to } 2 \\
\text { hours. } \\
\text { Frequency: once per day } \\
\text { or few times per month. } \\
\text { Lower limb dystonia. }\end{array}$ & $\begin{array}{l}\text { Duration of episodes: } \\
\text { seconds to minutes. } \\
\text { Frequency: up to } 100 \text { times } \\
\text { per day. } \\
\text { Dystonia, chorea, or } \\
\text { athetosis_usually } \\
\text { unilateral. }\end{array}$ & $\begin{array}{l}\text { Duration of episodes: } \\
\text { minutes to hours, } \\
\text { sometimes up to a day. } \\
\text { Frequency: few episodes } \\
\text { per week or just a few } \\
\text { episodes in a lifetime. } \\
\text { Dystonia, chorea or } \\
\text { athetosis involving } \\
\text { one limb and gradually } \\
\text { spreading to other limbs } \\
\text { and face. }\end{array}$ & $\begin{array}{l}\text { PNKD and epilepsy, either } \\
\text { in the form of absence or } \\
\text { GTC seizures. }\end{array}$ & $\begin{array}{l}\text { Focal, tonic, clonic, } \\
\text { myoclonic and } \\
\text { absence of seizures, } \\
\text { along with episodes } \\
\text { sometimes resembling } \\
\text { PKD. }\end{array}$ & $\begin{array}{l}\text { Epilepsy and PED, } \\
\text { usually embedded } \\
\text { in a more complex } \\
\text { syndrome of } \\
\text { lactic acidosis and } \\
\text { encephalopathy (Leigh- } \\
\text { like syndrome). }\end{array}$ \\
\hline Triggers & $\begin{array}{l}\text { Prolonged exercise, } \\
\text { and rarely by muscle } \\
\text { vibration, cold or } \\
\text { passive movements. }\end{array}$ & $\begin{array}{l}\text { Sudden movement, such } \\
\text { as sudden acceleration } \\
\text { or change in direction of } \\
\text { movement, or startle. }\end{array}$ & $\begin{array}{l}\text { Caffeine, alcohol, fatigue } \\
\text { or emotional stress. }\end{array}$ & & & \\
\hline $\begin{array}{l}\text { Additional } \\
\text { disorders related } \\
\text { to causative gene }\end{array}$ & $\begin{array}{l}\text { GLUT1DS: early-onset } \\
\text { refractory seizures and } \\
\text { MDs (dystonia, chorea, } \\
\text { myoclonus and PED). }\end{array}$ & $\begin{array}{l}\text { BFIS: AD syndrome } \\
\text { characterised by brief } \\
\text { seizures featuring motor } \\
\text { arrest, cyanosis, hypertonia } \\
\text { and limb jerks. } \\
\text { ICCA: infantile convulsions } \\
\text { followed by PKD. }\end{array}$ & & & & \\
\hline
\end{tabular}

$A D$, autosomal dominant; $B F I S$, benign familial infantile seizures; ECHS1, gene encoding PDC subunits; GLUT1DS, glucose transporter type-1 deficiency syndrome; GTC, generalised tonic-clonic seizures; ICCA, infantile convulsions and choreoathetosis syndrome; KNCMA1, gene encoding for a subunit of a calcium-activated potassium channel; MDs, movement disorders; PDC, pyruvate dehydrogenase complex;PED, paroxysmal exercise-induced dyskinesia; PKD, paroxysmal kinesigenic dyskinesia; PNKD, paroxysmal nonkinesigenic dyskinesia; SCN8A, encodes the alpha subunit of the sodium channel Nav1.

Focal seizures with motor-onset symptoms can be mistaken for different MDs. For example, automatisms in FIAS may mimic orofacial dyskinesia, focal tonic seizures may be interpreted as dystonia, and focal clonic seizures may be interpreted as transient tremor. Ictal EEG may be negative in FAS.

EPC is a rare type of focal SE that may last from days to years, and its characteristic semiological features are spontaneous regular or irregular muscular twitching that may wax and wane and affects a limited part of the body. ${ }^{43}$ EPC is sometimes aggravated by action or sensory stimuli, occurring for a minimum of 1 hour and recurring at intervals of no more than $10 \mathrm{s.}{ }^{43}$ Common causes of EPC are cerebrovascular disease and tumours in adults and Rasmussen encephalitis in children, followed by metabolic, toxic and other immune-mediated causes. Of note, hyperosmolar hyperglycaemic (a treatable metabolic emergency that requires prompt and accurate diagnosis) can present a broad spectrum of neurological manifestations including EPC, focal seizures and hemichorea-hemiballism. ${ }^{44}$

Nocturnal frontal lobe epilepsy (NFLE) is characterised by brief ( $<2 \mathrm{~min}$ ) and highly stereotyped and sometimes violent limb movements, or tonic-dystonic postures during sleep, or complex body movements with kicking or cycling of limbs and rocking body movements; vocalisation may also occur. ${ }^{45}$ A recent consensus conference suggested the term sleep-related hypermotor epilepsy due to the fact that many documented cases arise from areas other than the frontal lobes. ${ }^{45}$ Seizures occur predominantly during sleep, primarily during non-REM sleep and can happen several times per night. The postictal phase may be very short, at times without any confusion. The main differential diagnosis is non-epileptic paroxysmal MDs occurring during sleep, which are often difficult to differentiate on the clinical ground alone unless EEG polysomnography is performed. ${ }^{34}$ Adding to the diagnostic difficulty, EEG is typically normal or may be masked by excessive movement artefact during the events. The high incidence of uninformative EEG emphasises the importance of other characteristics in the differential diagnosis (eg, the highly stereotyped nature of the episodes). Mutations in CHRNA4, KCNT1 and DEPDC5 have been associated with NFLE; however, most of the cases are non-familial and often the genetic cause is not found. ${ }^{45}$

Progressive myoclonus epilepsies (PME) comprise a disabling group of rare disorders characterised by the coexistence of myoclonus, ataxia and epilepsy (table 3). ${ }^{46}$ Myoclonus is present at rest, but it can be triggered by movement, noise, light or touch. Recently, new PME genes have been reported, such as Neuroserpin, AFG3L2, GOSR2, SCARB2 and PRICKLE1. ${ }^{47-49}$

Head drops as a seizure manifestation are abrupt and often repetitive episodes of neck atonia occurring from one to several times per day in a regular or irregular fashion, and are often part of epileptic syndromes like myoclonic-astatic epilepsy, myoclonic epilepsy of infancy or severe epileptic encephalopathies. ${ }^{50}$ Infantile spasms or West syndrome is a severe condition often associated with intractable epilepsy and developmental delay, and may evolve into Lennox-Gastaut syndrome. Infantile spasms 
Table 3 Progressive myoclonic epilepsies

\begin{tabular}{|c|c|c|c|c|c|c|c|}
\hline & Inheritance & Seizure type & Myoclonus & $\begin{array}{l}\text { Intellectual } \\
\text { disability }\end{array}$ & $\begin{array}{l}\text { Cerebellar } \\
\text { features }\end{array}$ & Additional clinical features & Diagnosis \\
\hline $\begin{array}{l}\text { Unverricht- } \\
\text { Lundborg } \\
\text { disease } \\
\text { (EPM1) }\end{array}$ & AR-CSTB gene. & $\begin{array}{l}\text { GTC and } \\
\text { myoclonic } \\
\text { epilepsy. }\end{array}$ & Action myoclonus. & Yes. & Yes. & $\begin{array}{l}\text { Microcephaly, dystonic posturing } \\
\text { and chorea in the limbs. }\end{array}$ & Genetic test. \\
\hline $\begin{array}{l}\text { Lafora body } \\
\text { disease (EPM2) }\end{array}$ & $\begin{array}{l}A R-E P M 2 A \text { or } E P M 2 B \\
\text { gene. }\end{array}$ & $\begin{array}{l}\text { GTC and } \\
\text { occipital } \\
\text { seizures. }\end{array}$ & $\begin{array}{l}\text { Spontaneous } \\
\text { myoclonus. }\end{array}$ & Yes. & No. & $\begin{array}{l}\text { Visual hallucinations and } \\
\text { progressive neurological } \\
\text { deterioration. }\end{array}$ & $\begin{array}{l}\text { Skin biopsy: Lafora bodies. } \\
\text { Genetic test. }\end{array}$ \\
\hline $\begin{array}{l}\text { Myoclonic } \\
\text { epilepsy with } \\
\text { ragged-red } \\
\text { fibres }\end{array}$ & $\begin{array}{l}\text { Maternally inherited- } \\
\text { mitochondrial DNA } \\
\text { mutations (tRNALys } \\
\text { gene). }\end{array}$ & GTC. & Yes. & Yes. & & $\begin{array}{l}\text { Ataxia, dementia, dystonia, } \\
\text { parkinsonism, tremor and chorea. } \\
\text { Other findings: hearing loss, } \\
\text { short stature, optic atrophy and } \\
\text { cardiomyopathy. }\end{array}$ & $\begin{array}{l}\text { Muscle biopsy: ragged-red } \\
\text { fibres. } \\
\text { Genetic test. }\end{array}$ \\
\hline $\begin{array}{l}\text { Neuronal ceroid } \\
\text { lipofuscinoses } \\
\text { (NCL), also } \\
\text { known as } \\
\text { Batten disease. }\end{array}$ & $\begin{array}{l}\text { Lysosomal storage group } \\
\text { of disorders. } \\
\text { AR or AD late-onset } \\
\text { forms. PPT1, TPP1, CLN3, } \\
\text { CLN5, CLN6, MFSD8, } \\
\text { CLN8, CTSD, DNAJC5, } \\
\text { CTSF, ATP13A2, GRN } \\
\text { and KCTD7 genes. }\end{array}$ & $\begin{array}{l}\text { GTC and } \\
\text { myoclonic } \\
\text { seizures } \\
\text { leading to early } \\
\text { death. }\end{array}$ & Action myoclonus. & Yes. & No. & $\begin{array}{l}\text { Visual loss is frequently seen. } \\
\text { In childhood, NCL is the most } \\
\text { common lysosomal disorder. The } \\
\text { adult type (Kuf's disease) is the } \\
\text { rarest of all the subtypes of NCL. }\end{array}$ & $\begin{array}{l}\text { Skin biopsy: curvilinear } \\
\text { profiles, fingerprint profiles } \\
\text { granular osmophilic } \\
\text { deposits. } \\
\text { Genetic test. }\end{array}$ \\
\hline $\begin{array}{l}\text { Dentatorubral- } \\
\text { pallidoluysian } \\
\text { atrophy } \\
\text { (DRPLA) }\end{array}$ & $\begin{array}{l}A D \text { - expansion of CAG } \\
\text { repeats in the DRPLA } \\
\text { gene. }\end{array}$ & & Yes. & Yes. & Yes. & $\begin{array}{l}\text { Choreoathetosis, dementia and } \\
\text { psychiatric symptoms. Patients } \\
\text { with a PME phenotype have } \\
\text { larger expansions ( } 62-79 \text { repeats) } \\
\text { and earlier age of onset ( }<20 \\
\text { years old). }\end{array}$ & Genetic test. \\
\hline $\begin{array}{l}\text { Sialidosis } \\
\text { (type I) }\end{array}$ & $\begin{array}{l}\text { AR lysosomal storage } \\
\text { disease caused by } \\
\text { mutation in the NEU1 } \\
\text { gene. }\end{array}$ & $\begin{array}{l}\text { Myoclonic } \\
\text { epilepsy. }\end{array}$ & Action myoclonus. & Yes. & Yes. & $\begin{array}{l}\text { Visual problems, hyper-reflexia, } \\
\text { ataxia (second or the third decade } \\
\text { of life). Type I is a milder variant } \\
\text { and type II is a more severe } \\
\text { variant with an earlier onset. }\end{array}$ & $\begin{array}{l}\text { Macular cherry-red spots } \\
\text { may be seen but it is not } \\
\text { pathognomonic. } \\
\text { Sialo-oligosaccharides in } \\
\text { urine. } \\
\text { Genetic test. }\end{array}$ \\
\hline
\end{tabular}

$A D$, autosomal dominant; $A R$, autosomal recessive; CAG, cytosine-adenine-guanine; EPM1, progressive myoclonic epilepsy type 1; GTC, generalised tonic-clonic seizures; PME, progressive myoclonic epilepsy.

are characterised by brief and symmetrical contraction of neck, trunk and arms several times per day. The head appears to drop while the arms often elevate. Epileptic head drops and infantile spasms can be associated with EEG changes or not. Moreover, sudden head movements resembling head drops are common in MDs and characterised by active head flexion or extension and can be seen in tic disorders (eg, TS), stereotypies (eg, 'head banging'), choreic syndromes (particularly in chorea-acanthocytosis) or paroxysmal dyskinesias. ${ }^{50}$

Rasmussen encephalitis is a rare and possibly autoimmune disorder affecting mostly children or young adults, and characterised by severe epilepsy, progressive hemiplegia and cognitive decline. ${ }^{51}$ About $50 \%$ of patients with Rasmussen encephalitis present with EPC, which may sometimes be confused with MDs. Hemiathetosis, hemidystonia and parkinsonism with a corticobasal syndrome phenotype have been described, but overall MDs are rare.

Dravet syndrome is an epileptic encephalopathy associated with mutations in the sodium channel alpha1 subunit gene (SCN1A) presenting hemiclonic, afebrile myoclonic, and focal or generalised onset seizures, usually resistant to treatment. ${ }^{52}$ Patients may present ataxia, 'crouch gait' (increased hip and knee flexion and ankle dorsiflexion throughout the stance phase), postural abnormalities (antecollis, camptocormia and Pisa syndrome) and mild parkinsonism with some degree of levodopa responsiveness. ${ }^{52}$

\section{TREATMENT APPROACHES}

The treatment of focal seizures if associated with an MD should begin with the medications demonstrated in randomised clinical trials to be effective and safe, in particular seizure type or epilepsy syndrome. Some antiepileptic drugs may exacerbate myoclonus when used in patients with generalised onset epilepsy; this effect is generally seen in patients with an epilepsy syndrome that includes myoclonus, for example, juvenile myoclonic epilepsy. Drugs reported to exacerbate myoclonus include carbamazepine, phenytoin, vigabatrin, gabapentin, pregabalin and lamotrigine. ${ }^{53}$

Certain antiepileptic drugs may have adverse effects, making them less desirable in a patient with a known MD. Several antiepileptic drugs can produce tremor, most notably valproate, with a clear dose-related effect. Valproate has also been associated with drug-induced parkinsonism. ${ }^{54}$ The following antiepileptic drugs have tremor listed in prescribing information: lacosamide, lamotrigine, topiramate, oxcarbazepine and tiagabine..$^{55}$ Phenytoin has been associated with rare reports of dyskinesias including chorea, dystonia and asterixis. ${ }^{56}$

Additionally, there is a significant overlap between the treatment of epilepsy and MDs as antiepileptic drugs can be beneficial to both. Essential tremor is often treated with primidone, topiramate (both first-line treatment) or gabapentin. ${ }^{57}$ Cortical myoclonus can be treated with levetiracetam, valproic acid and clonazepam as first-line agents, whereas subcortical and brainstem 


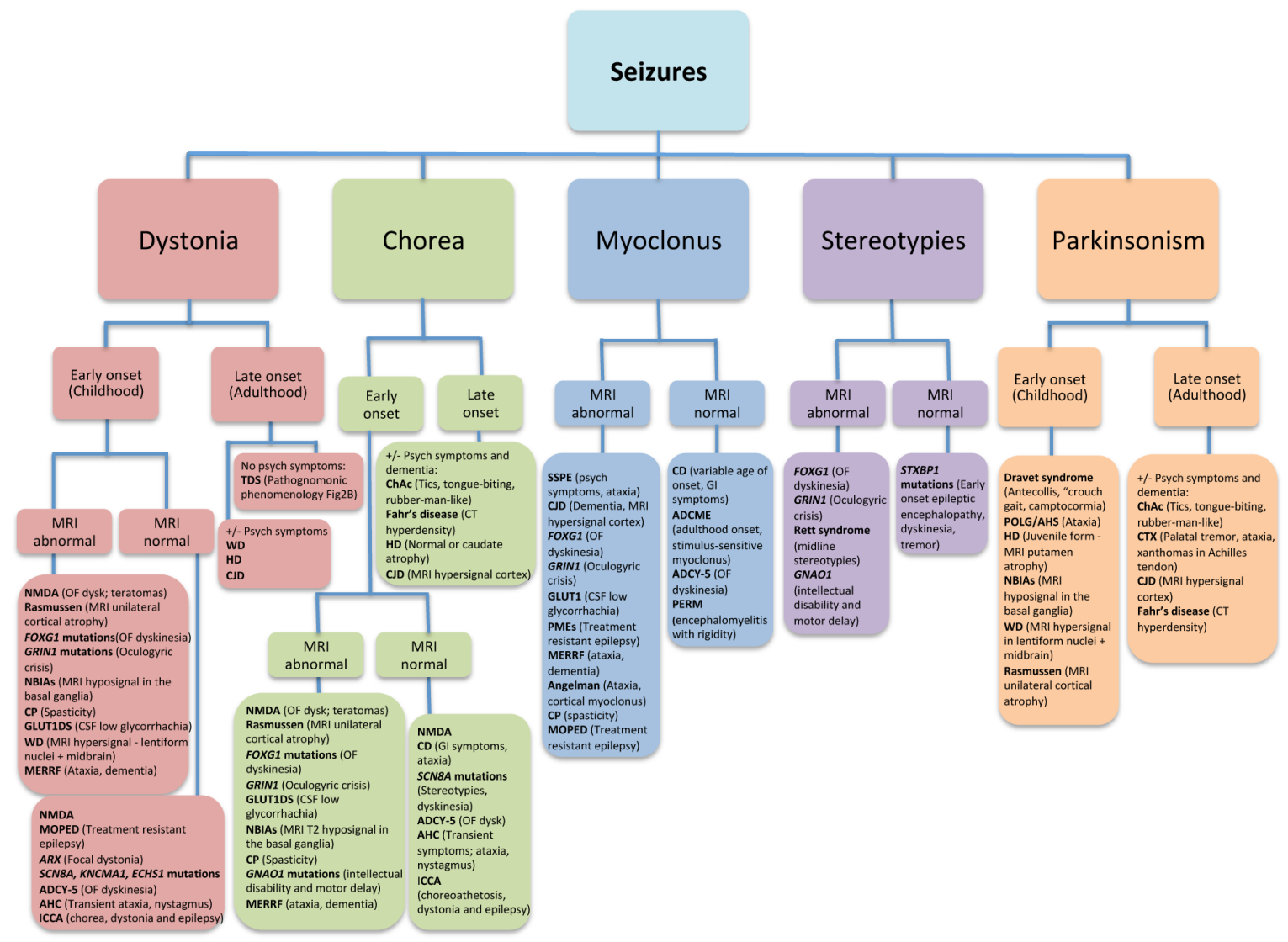

Figure 2 Diagnostic approach to patients with seizures and movement disorders. ADCME, autosomal dominant cortical tremor, myoclonus and epilepsy; ADCY-5, adenylyl cyclase 5 mutations; AHC, alternating hemiplegia of childhood; AHS/POLG, Alpers-Huttenlocher syndrome due to POLG mutation; CD, coeliac disease; ChAc, chorea-acanthocytosis; CJD, Creutzfeldt-Jakob disease; CP, Cerebral palsy; CSF, cerebrospinal fluid; CTX, cerebrotendinous xanthomatosis; GI, gastrointestinal; GLUT1DS, glucose transporter type-1 deficiency syndrome; GNA01, GNAO1 variants; HD, Huntington's disease; ICCA, infantile convulsions and choreoathetosis syndrome; NBIA, neurodegeneration with iron accumulation; NMDA, anti-N-methyl-D-aspartate receptor encephalitis; MERRF, myoclonic epilepsy with ragged red fibres; MOPED, myoclonic occipital photosensitive epilepsy with dystonia; OF, orofacial; PERM, progressive encephalomyelitis with rigidity and myoclonus; PME, progressive myoclonic epilepsies; psych, psychiatric; SSPE, subacute sclerosing panencephalitis; TDS, tonic-dystonic seizures; WD, Wilson's disease.

myoclonus can be treated with clonazepam as a first-line agent, but levetiracetam and valproic acid can be tried as well. ${ }^{53}$ PKD usually responds well to anticonvulsants like carbamazepine and phenytoin, often in low doses. Other anticonvulsants can also be tried, such as topiramate, levetiracetam, lamotrigine, valproate, oxcarbazepine and phenobarbital. ${ }^{37}$ Conversely, in PNKD, antiepileptic drugs are not always effective. ${ }^{37}$

\section{PATHOPHYSIOLOGY}

Traditionally, epilepsy has been considered a disorder originating from the cerebral cortex, while MDs have mostly been construed to reflect a dysfunction in subcortical areas. However, a net distinction between the pathophysiology of purely subcortical and cortical events risks to be an oversimplification owing to strong reciprocal connections between the basal ganglia and the cerebral cortex, particularly within the frontostriatal pathway. For instance, in one case with epilepsy and paroxysmal dyskinesia, the epileptogenic source was identified within the supplementary sensory motor cortex, but the ictal discharge rapidly spread to the basal ganglia. ${ }^{58}$ In patients with SLC2A1 mutations manifesting with epilepsy and PED, ictal single -photon emission computed tomography (SPECT) demonstrated the involvement of a network including both basal ganglia and cortical motor areas. ${ }^{59}$ Similarly, electrodecremental events have been described as the ictal EEG correlates of TDS associated with LGI1 antibodies. ${ }^{25}$ Some authors argue that simultaneous pathogenic involvement of the basal ganglia and the cortex may explain the overlap of cortical (epileptic) and subcortical (MDs) features of these spells, as further suggested by a positron-emission tomography (PET) study showing a concomitant involvement of the motor cortex, the hippocampus and of the striatum. ${ }^{60}$ It should be noted, however, that metabolic connectivity does not necessarily reflect anatomical connectivity but rather the coupled energy demand of different brain areas. ${ }^{61}$ Therefore, it is not surprising that disorders in which energy failure represents the main pathomechanism (eg, GLUT1DS, ECHS1 mutations or PDC deficiency) might display both epilepsy and MDs, as a function of energy failure of both cortical and subcortical areas, regardless of their interconnectivity.

These notions can be applied to many other epileptic conditions. For example, different distribution of subcortical dopaminergic dysfunction can be seen in epileptic syndromes using PET studies with dopamine transporter ligand. Patients with juvenile myoclonic epilepsy have shown lower tracer binding in the midbrain, whereas patients with GTC had reduced binding in the putamen. ${ }^{62}$

Similarly, the regional distribution of the products of mutated genes at both cortical and subcortical levels has been suggested 
to represent another mechanism whereby epilepsy and MDs might coexist in conditions genetically determined. This might be the case, for instance, of PRRT2 that is highly expressed at both sites. $^{37}$

In contrast to PRRT2 mutations, PNKD mutations encompass paroxysmal MDs but not seizure, although they are also expressed at the cortical level. ${ }^{37}$ Other mechanisms are therefore possible. In fact, striatal neurons are more susceptible than cortical ones to PNKD dysfunction, suggesting that neuronal vulnerability to specific pathomechanisms might also account for the relative risk of seizure across different MDs. ${ }^{37}$

Furthermore, mutation type might further modulate epilepsy risk. As an example, $S C N 8 A$ mutations associated with gain-offunction and high channel activity typically result in epileptic encephalopathy, whereas loss-of-function SCN8A mutations, which impair trafficking of the channel protein, are associated with isolated intellectual disability or MDs without seizures. ${ }^{63}$

\section{CONCLUSIONS AND FUTURE DIRECTIONS}

Despite being distinct neurological conditions, seizures and MDs present abnormal and involuntary movements with a well-defined phenomenology overlap, but with different pathophysiology. The clinical diagnosis can be challenging, and while a positive EEG is a useful tool to provide supporting evidence towards a diagnosis of seizure, a negative EEG has limited utility. In a few cases, the boundaries are well established, for instance in EPC and NFLE (epileptic origin) or in paroxysmal dyskinesia and SD (well-known MDs). However, these boundaries are blurred in disorders manifesting seizures and MDs concomitantly. These conditions represent the majority of cases discussed in our review, and although the clinical diagnosis can be more challenging, the correct definition of the MDs associated with seizure can adequately inform the diagnostic process. Our extensive review of the literature allowed us to propose an algorithm to facilitate the clinical approach, improve the diagnostic accuracy and guide clinicians who face these challenges in their daily practice (figure 2).

Contributors MEF: design and conceptualised study; analysed the data; drafted the manuscript and tables; revised the manuscript for intellectual content. MR-L: analysed the data; drafted the manuscript and tables; revised the manuscript for intellectual content. JD: drafted and revised the manuscript for intellectual content. RE: drafted and revised the manuscript for intellectual content. MP: drafted and revised the manuscript for intellectual content. DA: analysed the data; drafted and revised the manuscript for intellectual content. AF: design and conceptualised the study; analysed the data; drafted the manuscript, tables and figures; revised the manuscript for intellectual content.

Funding The authors have not declared a specific grant for this research from any funding agency in the public, commercial or not-for-profit sectors.

Competing interests JD reports grants and non-financial support from Euroimmun. RE reports personal fees from TEVA, personal fees from Zambon and from Cambridge University Press. MP reports grants from Epilepsy Foundation, grants and personal fees from GW Pharma, grants and personal fees from SK Life Science, grants from Sage, grants from NIH, personal fees from Astellas and personal fees from Upsher-Smith. DA reports grants from Dravet.ca, grants from Ontario Brain Institute, and grants from McLaughlin Foundation, Eisai and Stoke. AF reports grants, personal fees and non-financial support from AbbVie, grants, personal fees and non-financial support from Boston Scientific, grants, personal fees and non-financial support from Medtronic, grants and personal fees from Sunovion, grants and personal fees from Ipsen, grants from Merz, personal fees from Chiesi, and personal fees from UCB.

Patient consent for publication Not required.

Provenance and peer review Not commissioned; externally peer reviewed.

\section{REFERENCES}

1 Stoessl AJ, Mckeown MJ, disorders M. Movement disorders. Handb Clin Neurol 2016;136:957-69.
2 Fisher RS, Cross JH, French JA, et al. Operational classification of seizure types by the International league against epilepsy: position paper of the ILAE Commission for classification and terminology. Epilepsia 2017;58:522-30.

3 Marras C, Lang A, van de Warrenburg BP, et al. Nomenclature of genetic movement disorders: recommendations of the international Parkinson and movement disorder society task force. Mov Disord 2016;31:436-57.

4 Scheffer IE, Berkovic S, Capovilla G, et al. ILAE classification of the epilepsies: position paper of the ILAE Commission for classification and terminology. Epilepsia 2017; $58: 512-21$

5 Feddersen B, Rémi J, Einhellig M, et al. Parkinson's disease: less epileptic seizures, more status epilepticus. Epilepsy Res 2014;108:349-54.

6 Gruntz K, Bloechliger M, Becker C, et al. Parkinson disease and the risk of epileptic seizures. Ann Neurol 2018:83:363-74.

7 Rodriguez-Castro KI, Hevia-Urrutia FJ, Sturniolo GC. Wilson's disease: a review of what we have learned. World J Hepatol 2015;7:2859-70.

8 Prashanth LK, Sinha S, Taly AB, et al. Spectrum of epilepsy in Wilson's disease with electroencephalographic, MR imaging and pathological correlates. J Neurol Sci 2010;291:44-51.

9 Savino E, Soavi C, Capatti E, et al. Bilateral strio-pallido-dentate calcinosis (Fahr's disease): report of seven cases and revision of literature. BMC Neurol 2016;16.

10 Batla A, Tai XY, Schottlaender L, et al. Deconstructing Fahr's disease/syndrome of brain calcification in the era of new genes. Parkinsonism Relat Disord 2017;37:1-10.

11 Nie S, Chen G, Cao X, et al. Cerebrotendinous xanthomatosis: a comprehensive review of pathogenesis, clinical manifestations, diagnosis, and management. Orphanet J Rare Dis 2014;9.

12 Schneider SA. Neurodegeneration with brain iron accumulation. Curr Neurol Neurosci Rep 2016;16.

13 Gövert F, Schneider SA. Huntington's disease and Huntington's disease-like syndromes: an overview. Curr Opin Neurol 2013:26:420-7.

14 Bates GP, Dorsey R, Gusella JF, et al. Huntington disease. Nat Rev Dis Primers 2015;1.

15 Benninger F, Afawi Z, Korczyn AD, et al. Seizures as presenting and prominent symptom in chorea-acanthocytosis with c.2343del VPS13A gene mutation. Epilepsia 2016;57:549-56

16 Rossi M, Perez-Lloret S, Doldan L, et al. Autosomal dominant cerebellar ataxias: a systematic review of clinical features. Eur I Neurol 2014;21:607-15

17 Tsuji S. Dentatorubral-pallidoluysian atrophy. Handb Clin Neurol 2012;103:587-94.

18 Striano P, Zara F. Autosomal dominant cortical tremor, myoclonus and epilepsy. Epileptic Disord 2016;18:139-44

19 Wong LC, Huang H-L, Weng W-C, et al. Increased risk of epilepsy in children with tourette syndrome: a population-based case-control study. Res Dev Disabil 2016;5152:181-7

20 Westenberger A, Max C, Brüggemann N, et al. Alternating hemiplegia of childhood as a new presentation of adenylate cyclase 5-mutation-associated disease: a report of two cases. J Pediatr 2017;181:306-8.

21 Carvajal-González A, Leite MI, Waters P, et al. Glycine receptor antibodies in perm and related syndromes: characteristics, clinical features and outcomes. Brain 2014:137:2178-92.

22 Dalmau J, Graus F. Antibody-mediated encephalitis. N Eng/ J Med 2018;378:840-51.

23 Graus F, Titulaer MJ, Balu R, et al. A clinical approach to diagnosis of autoimmune encephalitis. Lancet Neurol 2016;15:391-404.

24 Schmerler DA, Roller S, Espay AJ. Teaching video neurolmages: faciobrachial dystonic seizures: pathognomonic phenomenology. Neurology 2016;86:e60-1.

25 van Sonderen A, Thijs RD, Coenders EC, et al. Anti-LGI1 encephalitis: clinical syndrome and long-term follow-up. Neurology 2016;87:1449-56.

26 Spatola M, Petit-Pedrol M, Simabukuro MM, et al. Investigations in $\mathrm{GAB}_{A \mathrm{~A}}$ receptor antibody-associated encephalitis. Neurology 2017;88:1012-20.

27 Kirshner HS. Hashimoto's encephalopathy: a brief review. Curr Neurol Neurosci Rep 2014;14.

28 Anlar B. Subacute sclerosing panencephalitis and chronic viral encephalitis. Handb Clin Neurol 2013:112:1183-9.

29 Manix M, Kalakoti P, Henry M, et al. Creutzfeldt-Jakob disease: updated diagnostic criteria, treatment algorithm, and the utility of brain biopsy. Neurosurg Focus 2015;39.

30 Mahboob HB, Kaokaf KH, Gonda JM. Creutzfeldt-Jakob disease presenting as expressive aphasia and nonconvulsive status epilepticus. Case Rep Crit Care 2018;2018:1-9.

31 Chaudhry N, Srivastava A, Joshi L. Hemifacial spasm: the past, present and future. J Neurol Sci 2015;356:27-31.

32 Espay AJ, Schmithorst VJ, Szaflarski JP. Chronic isolated hemifacial spasm as a manifestation of epilepsia partialis continua. Epilepsy Behav 2008;12:332-6.

33 Haba-Rubio J, Marti-Soler H, Marques-Vidal P, et al. Prevalence and determinants of periodic limb movements in the general population. Ann Neurol 2016;79:464-74.

34 Nguyen-Michel V-H, Solano O, Lambrecq V, et al. Complex periodic limb movements during sleep or partial epileptic seizures? Neurology 2015;85.

35 Ruiz-Lopez M, Fasano A. Rethinking status dystonicus. Mov Disord 2017;32:1667-76

36 Ure RJ, Dhanju S, Lang AE, et al. Unusual tremor syndromes: know in order to recognise. J Neurol Neurosurg Psychiatry 2016;87:1191-203. 
37 Erro R, Bhatia KP, Espay AJ, et al. The epileptic and nonepileptic spectrum of paroxysmal dyskinesias: channelopathies, synaptopathies, and transportopathies. Mov Disord 2017;32:310-8.

38 Gardiner AR, Jaffer F, Dale RC, et al. The clinical and genetic heterogeneity of paroxysmal dyskinesias. Brain 2015;138:3567-80.

39 Pearson TS, Akman C, Hinton VJ, et al. Phenotypic spectrum of glucose transporter type 1 deficiency syndrome (GLUT1 Ds). Curr Neurol Neurosci Rep 2013;13.

40 Olgiati S, Skorvanek M, Quadri M, et al. Paroxysmal exercise-induced dystonia within the phenotypic spectrum of ECHS1 deficiency. Mov Disord 2016;31:1041-8.

41 Dreissen YEM, Tijssen MAJ. The startle syndromes: physiology and treatment. Epilepsia 2012;53 Suppl 7:3-11.

42 Chang FCF, Westenberger A, Dale RC, et al. Phenotypic insights into ADCY5associated disease. Mov Disord 2016;31:1033-40.

43 Atmaca MM, Bebek N, Kocasoy-Orhan E, et al. Epilepsia partialis continua: correlation of semiology, outcome and electrophysiologic features. Clin Neurol Neurosurg 2018;171:143-50.

44 Misra UK, Kalita J, Bhoi SK, et al. Spectrum of hyperosmolar hyperglycaemic state in neurology practice. Indian J Med Res 2017;146(Supplement):1-S7.

45 Tinuper $\mathrm{P}$, Bisulli F, Cross JH, et al. Definition and diagnostic criteria of sleep-related hypermotor epilepsy. Neurology 2016;86:1834-42.

46 Malek N, Stewart W, Greene J. The progressive myoclonic epilepsies. Pract Neurol 2015;15:164-71.

47 Dibbens L, Schwake M, Saftig P, et al. SCARB2/LIMP2 deficiency in action myoclonusrenal failure syndrome. Epileptic Disord 2016;18:63-72.

48 Dibbens LM, Rubboli G. GOSR2: a progressive myoclonus epilepsy gene. Epileptic Disord 2016:18:111-4.

49 Eskandrani A, AlHashem A, Ali E-S, et al. Recessive AFG3L2 mutation causes progressive microcephaly, early onset seizures, spasticity, and basal ganglia involvement. Pediatr Neurol 2017;71:24-8.

50 Antelmi E, Plazzi G, Erro R, et al. Intermittent head drops: the differential spectrum. J Neurol Neurosurg Psychiatry 2016;87:414-9.
51 Varadkar S, Bien CG, Kruse CA, et al. Rasmussen's encephalitis: clinical features, pathobiology, and treatment advances. Lancet Neurol 2014;13:195-205.

52 Fasano A, Borlot F, Lang AE, et al. Antecollis and levodopa-responsive parkinsonism are late features of dravet syndrome. Neurology 2014;82:2250-1.

53 Levy A, Chen R. Myoclonus: pathophysiology and treatment options. Curr Treat Options Neurol 2016;18.

54 Brugger F, Bhatia KP, Besag FMC. Valproate-Associated parkinsonism: a critical review of the literature. CNS Drugs 2016;30:527-40.

55 Nevitt SJ, Sudell M, Weston J, et al. Antiepileptic drug monotherapy for epilepsy: a network meta-analysis of individual participant data. Cochrane Database Syst Rev 2017; 12 .

56 González Otárula KA, Ugarnes G, Rossi M, et al. Phenytoin-induced chorea: drug interaction or genetic predisposition? Clin Neuropharmacol 2016:39.

57 Haubenberger D, Hallett M, Tremor E. Essential tremor. N Engl J Med 2018:379:1802-10.

58 van Strien TW, van Rootselaar A-F, Hilgevoord AAJ, et al. Paroxysmal kinesigenic dyskinesia: cortical or non-cortical origin. Parkinsonism Relat Disord 2012;18:645-8.

59 Suls A, Dedeken P, Goffin K, et al. Paroxysmal exercise-induced dyskinesia and epilepsy is due to mutations in SLC2A1, encoding the glucose transporter GLUT1. Brain 2008;131:1831-44.

60 Navarro V, Kas A, Apartis E, et al. Motor cortex and hippocampus are the two main cortical targets in LGI1-antibody encephalitis. Brain 2016;139:1079-93.

61 Lee DS, Kang H, Kim H, et al. Metabolic connectivity by interregional correlation analysis using statistical parametric mapping (SPM) and FDG brain PET; methodological development and patterns of metabolic connectivity in adults. Eur J Nucl Med Mol Imaging 2008;35:1681-91.

62 Ciumas C, Wahlin T-BR, Espino C, et al. The dopamine system in idiopathic generalized epilepsies: identification of syndrome-related changes. Neuroimage 2010;51:606-15.

63 Wagnon JL, Barker BS, Ottolini M, et al. Loss-of-function variants of SCN8A in intellectual disability without seizures. Neurol Genet 2017;3. 